\title{
Líderes femininas em organizações esportivas - Tendências mundiais
}

\author{
Gertrud Pfister*
}

\begin{abstract}
Resumo: a presente pesquisa objetiva discutir a liderança feminina em organizações esportivas. Para tanto recorre a uma análise a partir de dados quantitativos de alguns países ocidentais com destaque no campo esportivo (Alemanha, Dinamarca, Estados Unidos e Austrália) ressaltando que, em termos de cargos dirigentes em instituições esportivas, as mulheres ainda não alcançaram o mesmo status que os homens. Tendo como referência teórica os estudos de gênero, a pesquisa evidencia que apesar do grande avanço que as mulheres obtiveram no mundo do esporte, quando se refere à liderança e a cargos diretivos há ainda muito a se conquistar.
\end{abstract}

Palavras-chave: Esporte, Gênero, Liderança Esportiva.

Nos séculos XVIII e XIX, o esporte e a ginástica foram inventados pelo homem e para o homem, eles que desenvolveram as atividades, práticas e performances esportivas de acordo com suas próprias necessidades e ideais. Até a Primeira Guerra Mundial, mulheres e meninas eram, de certo modo, banidas dos campos esportivos sendo confinadas às laterais, de onde podiam admirar os atletas. Se tivessem permissão para serem fisicamente ativas, deveriam praticar calistenia objetivando o bem da sua saúde. Assim, Johann Adolf Ludwig Werner, um dos "pais" alemães da ginástica para meninas, exalta os efeitos positivos da atividade física: "O aumento da força muscular vai proteger [meninas] das aflições da vida e das desordens físicas, já que a maioria das deformações da espinha é resultado de fraqueza muscular; sua beleza vai aumentar devido, primeiramente, ao desabrochar e arredondar de seus corpos delicados, que será fruto da sua boa saúde, e, em segundo lugar, à graça com que vão realizar os movimentos" (Pfister 1980, p. 17; Pfister 1990).

Hoje, o esporte ainda é um mundo masculino, mas as mulheres estão fazendo sentir a sua presença. Um indicador importante da crescente integração da mulher no esporte é a sua participação

* Instituto de Ciências do Exercício e do Esporte, Universidade de Copenhagen.

Movimento Porto Alegre, v. 09, n. 2, p. 11-35, maio/agosto de 2003 
em quase todos os tipos de modalidades esportivas onde até mesmo o futebol, o boxe e o salto com esqui não são mais "apenas para homens". No entanto, deve-se manter em mente que as atletas praticantes de "esportes masculinos" são uma pequena minoria de jovens mulheres e que a revolução das atividades físicas femininas é restrita, principalmente, aos países industrializados. Essa afirmação é evidenciada, também, pelas contribuições de livro sobre esportes femininos que incluiu informações de dezesseis países de todo o mundo e que foi editado por mim e minha colega Ilse Hartmann-Tews. Os artigos deste livro revelam muitas diferenças que vão desde as modalidades de esportes definidas como masculinas e femininas às estruturas dos sistemas esportivos, sendo um o fator comum em todos os países envolvidos: o poder estava e está nas mãos dos homens.

No presente artigo, dividirei com vocês informações sobre a participação das mulheres em comitês deliberativos ligados ao Movimento Olímpico e em outras federações nacionais; descreverei as relações de gênero e hierarquia existentes nas federações esportivas em países selecionados. Além disso, discutirei as razões e os motivos para o desequilíbrio de poder e fornecerei algumas explicações a esse respeito.

\section{A Organização Internacional e o COI}

Durante sua vida, o Barão de Coubertin, o fundador dos Jogos Olímpicos Modernos e um homem típico do seu tempo, pensava que as mulheres não deveriam macular os jogos com seu suor, mas, meramente, coroar as vitórias. Entretanto, apenas obteve sucesso na total exclusão das mulheres, uma vez, em 1896, e mesmo assim duas participaram, extra-oficialmente, da maratona. Apesar da resistência de Coubertin e de muitos dos seus partidários, as mulheres participam oficialmente dos jogos desde 1900 (Pfister 2000). De lá para cá, a proporção de atletas femininas nos Jogos Olímpicos cresceu de 0\%, em 1896, a cerca de $40 \%$ em 2000.

Porém, o crescente número de participantes femininas em competições olímpicas não levou a uma divisão igual de poder e influência. Por muito tempo o Comitê Olímpico Internacional (COI) foi um "clube masculino" que, desde o princípio, negou totalmente o acesso às mulheres. Foi apenas em 1981 que as primeiras duas mulheres, Pirjo Haggmann (Finlândia) e Flor 
Isava-Fonseca (Venezuela) foram cooptadas para dentro do COI. Em 1995, sete dos cento e sete seus membros eram mulheres. Entretanto, desde a metade da década de 90 o COI toma iniciativas objetivando aumentar o número de líderes femininas nas organizações esportivas. Em 1996, pediu aos seus membros que aumentassem a participação feminina em comitês deliberativos para $10 \%$ em 2000 e para $20 \%$ em 2002 . A promoção de mulheres é política oficial do COI e está ancorada na Carta Olímpica: “O Comitê Olímpico Internacional encoraja intensamente, por meios apropriados, a promoção de mulheres no esporte em todos os níveis e em todas as estruturas, particularmente nas federações de organizações esportivas nacionais e internacionais em vista da rigorosa aplicação do princípio de igualdade do homem e da mulher" (parágrafo 5, Carta Olímpica, Regra 2, n. 5). ${ }^{1}$

Mas, apesar das intenções e esforços, a situação não mudou decisivamente: em 2001, quando $10 \%$ dos membros deveriam ter sido mulheres, entre cento e vinte e seis membros do COI apenas onze eram mulheres $(8,7 \%)$. Portanto, nem o próprio COI foi capaz de alcançar as exigências que impôs a seus membros. Hoje, a situação não mudou decisivamente, já que o COI é formado por doze mulheres e cento e quatorze homens, sendo que nenhuma das participantes vem da África "negra", nem do sudeste da Ásia ou da América Latina. Uma mulher - Gunila Lindberg, Suécia - e treze homens formam o seu Conselho Executivo e, tanto o presidente como os quatro vice-presidentes, são homens.

Também as várias comissões existentes no COI são dominadas por homens. A comissão de ética, por exemplo, tem sete homens e 1 mulher como membros, a comissão de marketing tem 17 homens e uma mulher; a de cultura e educação Olímpica tem vinte e três homens e quatro mulheres e, no Comitê para Solidariedade Olímpica, são quinze homens e não há uma só mulher. Cabe ressaltar que a maioria dos participantes de comitês são membros do COI, mas existem, também, especialistas de fora que são incluídos no Comitê. ${ }^{2}$

1 Ver a webpage do COI em http://www.olympic.org/uk/organisation/commissions/ women/index_uk.asp, acessada em 10.5.2003; ver também Mascagni Stivachtis 2000, 33.

2 A informação vem da webpage do COI; http://www.olympic.org/uk/organisation/ index_uk.asp, acessada em 10.5.2003.

Movimento Porto Alegre, v. 09, n. 2, p. 11-35, maio/agosto de 2003 
Não apenas no Comitê Olímpico Internacional, mas também nos Comitês Olímpicos Nacionais, assim como nas federações esportivas internacionais, os dirigentes quase sempre têm sido homens. Em 2000, apenas três dos cento e noventa e nove Comitês Olímpicos Nacionais (CONs) foram presididos por mulheres e menos de $25 \%$ tiveram mulheres em cargos executivos como vice-presidentes ou secretárias gerais e $42 \%$ tiveram mulheres nos conselhos (Ferris 2000).O maior número de mulheres participantes nos conselhos dos CONs se encontraram no Canadá e na Romênia, com cinco em cada um deles. Em 2002, cento e treze dos duzentos CONs alcançaram a meta imposta pelo COI, ou seja, as mulheres chegaram a $10 \%$ dos membros nos comitês deliberativos (Ministerium für Städtebau 2003, 25). Ainda assim, as mudanças nos números não dizem nada a respeito de influência e poder. As mulheres, por exemplo, ainda são excluídas de participação em reuniões internacionais, como revelou Gunilla Lindberg, a única mulher no Conselho Executivo do COI, em um discurso no congresso anual do ANOC no Rio de Janeiro (2000) onde, dos quatrocentos delegados de cento e noventa e dois Comitês Nacionais, trezentos e noventa e dois eram homens e oito mulheres (Lindberg 2003).

Também nas federações esportivas mundiais os homens dominam os comitês deliberativos e as mulheres têm, quanto muito, um papel secundário. Uma pesquisa da Fundação Atlética Amadora, em Los Angeles, no começo dos anos 90 mostrou que apenas 5\% dos aproximadamente treze mil cargos em comitês deliberativos em organizações esportivas internacionais foram preenchidas por mulheres (DeFrantz 1991, 416). Em 2000, em 35,5\% das sessenta e uma federações de esportes olímpicos as mulheres tinham "posições-chave no corpo executivo", sendo que cinco federações tinham eleito uma mulher como presidente e três como a secretária geral. (Ferris 2000, 34).

\section{As relações de gênero nas organizações esportivas - Líderes masculinos e femininos em países selecionados}

Nesta parte do meu ensaio, gostaria de dividir com vocês informações a respeito de relações de gênero no topo da hierarquia esportiva. Deve-se, primeiramente, levar em consideração que o esporte tem diferentes significados, em diferentes línguas

Movimento Porto Alegre, v. 09, n. 2, p. 11-35, maio/agosto de 2003 
e diferentes culturas; eu uso "esporte", aqui, como um termo abrangente que inclui atividades físicas da ginástica ao fitness. É necessário considerar, ainda, que o esporte é organizado e estruturado de maneiras diferentes em diferentes países. Também as tradições, valores e expectativas ligadas ao esporte, as suas imagens e mensagens, as modalidades, assim como a participação da população no esporte variam consideravelmente. O espantoso é que, apesar de todas essas diferenças, há uma semelhança: a hierarquia do sexo e o desequilíbrio de poder em organizações e instituições esportivas.

Não posso apresentar informações de todos os países, nem mesmo de todos os países apresentados no nosso já citado anteriormente. Posso apenas apresentar alguns exemplos. Para comparar as relações de gênero nas organizações esportivas e para identificar o papel das estruturas esportivas, escolhi países com estruturas esportivas diferentes, mas com relações de gênero semelhantes bem como uma atitude semelhante em relação à igualdade de ambos os sexos. Além disso, a seleção de países também teve razões práticas, ou seja, a disponibilidade de informação em uma das línguas ocidentais. Ainda assim penso que uma pesquisa mundial a respeito do gênero, estruturas esportivas e liderança é um importante projeto para o futuro.

\section{Alemanha}

Vamos começar com a Alemanha, um país onde o esporte está baseado, em larga escala, nos clubes e em trabalho voluntário. As organizações esportivas são autônomas, mas apoiadas pelos governos federais ou regionais de acordo com o princípio dos subdsídios. Isto é, o Estado (governo federal e regional e comunidade) fornece recursos financeiros "adicionais" para certas atividades como, por exemplo, o esporte de elite ou esporte juvenil, se os recursos financeiros das organizações esportivas não forem suficientes. Os membros dos comitês dirigentes das federações esportivas regionais, as federações dos diferentes tipos de esporte (federação de futebol, de ginástica, etc.) e a federação coordenadora, a Confederação Alemã de Esporte, são todos voluntários, ou seja, não são funcionários pagos.

Cerca de um terço da população da Alemanha, aproximadamente vinte e cinco milhões de pessoas, são membros de um clube esportivo, nove milhões (ou 39\%) destes membros são mulheres ou meninas. Entretanto, existe uma enorme diferença

Movimento Porto Alegre, v. 09, n. 2, p. 11-35, maio/agosto de 2003 
nas diversas modalidades: enquanto a Federação Alemã de Ginástica, com quase cinco milhões de membros (a segunda maior federação), tem mais de $70 \%$ de mulheres, a Federação Alemã de Futebol (a maior federação esportiva, com mais de seis milhões de membros) tem $90 \%$ de homens e meninos como membros. $^{3}$

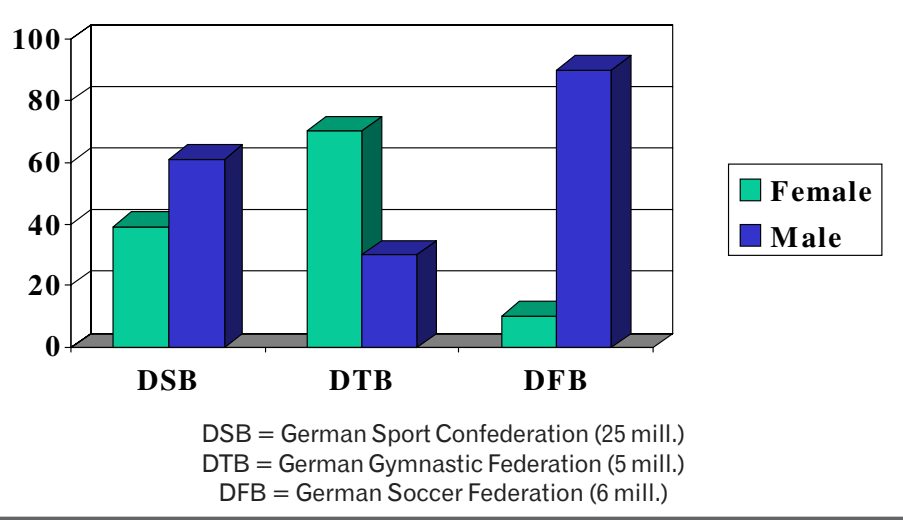

Figura 1. Members of German Sport Federations

A integração de mulheres nas estruturas de liderança da Confederação Alemã de Esporte (DSB) segue um padrão claro: quanto maior a posição, menor a porcentagem de mulheres. A distribuição de mulheres nos diferentes níveis lembra uma pirâmide, a porcentagem de instrutoras corresponde ao número de sócias (37\%), enquanto os esportes de alto nível quase sempre representam uma zona "livre de mulheres".

No comitê executivo da Confederação Alemã de Esporte, sempre houve uma ou duas mulheres como membros, uma delas sendo a representante do comitê feminino, eleita pelos membros femininos. Também hoje há apenas duas mulheres entre os onze maiores dirigentes no esporte alemão. ${ }^{4}$

3 Ver as estatísticas de associados do DSB, que são publicadas todo ano. DSB: Bestandserhebung. Frankfurt 2002.

4 Ver os anuários da Confederação Alemã de Esporte; DSB: Jahrbuch des Sports. Frankfurt 2002.

Movimento Porto Alegre, v. 09, n. 2, p. 11-35, maio/agosto de 2003 
A situação é ainda pior nas cinqüenta e cinco federações de esportes específicos, onde apenas $10 \%$ dos cargos dirigentes são de mulheres. Destas, vinte e duas federações não possuem sequer uma mulher no seu mais alto comitê, incluindo basquete, futebol e tênis.

Nos comitês mais altos das dezesseis federações dos dezesseis Estados da Alemanha, a porcentagem de mulheres está entre $12 \%$ e $40 \%$, com uma média em torno de $20 \%$ (Pfister/ Meck 2003).

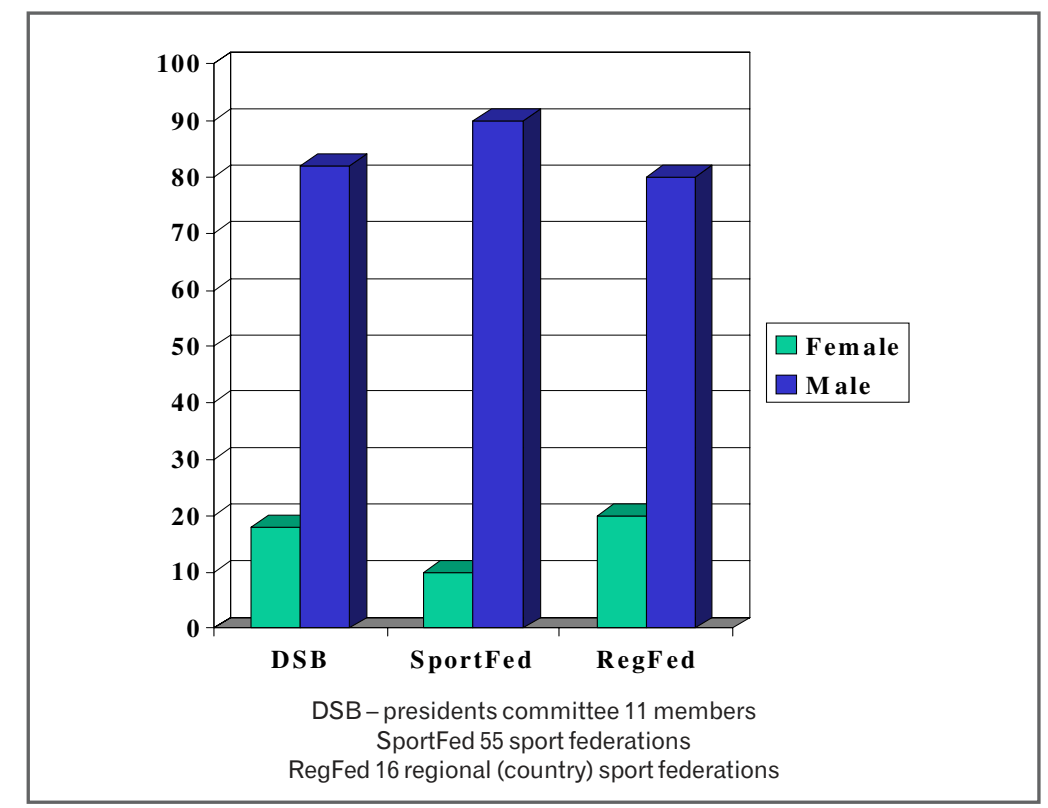

Figura 2. Female leaders in German sport organisations

A hierarquia baseada no sexo nas organizações esportivas é acompanhada de uma segregação horizontal. As mulheres nos comitês executivos das Federações Esportivas dos dezesseis estados alemães têm tarefas diferentes das dos homens, geralmente responsáveis pelo trabalho com mulheres e jovens, enquanto os homens são os presidentes e responsáveis por finanças (Pfister/Meck 2003).

As federações esportivas específicas no nível federal têm também uma estrutura regional: isso significa, por exemplo, que

Movimento Porto Alegre, v. 09, n. 2, p. 11-35, maio/agosto de 2003 
a Federação Alemã de Ginástica é formada por vinte Federações Regionais de Ginástica, tais como: a Federação Bavária de Ginástica, a Federação Baixo-Saxã de Ginástica e assim por diante. ${ }^{5}$ Analisar melhor o sexo e o poder na Federação Alemã de Ginástica é particularmente interessante já que $70 \%$ dos membros são garotas e mulheres (Pfister 1998). A análise das relações de gênero na Federação Alemã de Ginástica, incluindo os comitês nos níveis mais baixos, assim como as federações regionais e seus subcomitês, revelam a seguinte imagem: em 1998, $24 \%$ das trezentas e trinta e duas posições nos diferentes comitês no nível federal do DTB (Federação Alemã de Ginástica) eram preenchidas por mulheres. Mesmo assim, algumas áreas de trabalho ainda estão totalmente nas mãos dos homens. Hoje, por exemplo, todos os Centros Olímpicos (Olimpiastützpunkte) são dirigidos por homens.

Nos comitês executivos das associações regionais de ginástica, as mulheres são representadas em um nível um pouco mais alto do que na DTB: $35 \%$ de um total de quase três mil posições são de mulheres. Mas isso é com um total de $70 \%$ de mulheres como membros votantes! Se considerarmos a representação da mulher nos comitês deliberativos como marca de nível, então, as mulheres nas federações esportivas estão em maioria, mas com pouco poder.

\section{Dinamarca}

A análise da situação dinamarquesa é especialmente interessante pois a Dinamarca é um país próspero que declara ter chegado à igualdade de sexos. Além disso tem um eficiente sistema de assistência à criança e uma alta taxa de emprego de mulheres.

Como na Alemanha, o esporte dinamarquês é baseado em clubes e federações que seguem o princípio de democracia, trabalho voluntário e reciprocidade. Em contraste com a Alemanha, existem três federações coordenadoras na Dinamarca que tem cinco milhões de habitantes. Existe uma pequena associação para grupos esportivos em empresas, a DFIF; a tradicional Associação Dinamarquesa de Ginástica (DGI), que é uma federação autônoma e responsável por diferentes tipos de esporte,

5 Em alguns Estados alemães existem duas confederações esportivas.

Movimento Porto Alegre, v. 09, n. 2, p. 11-35, maio/agosto de 2003 
mas apenas no nível de "esporte para todos"e, por fim, existe a Federação Dinamarquesa de Esporte (DIF), que é formada pelas várias federações esportivas e organiza desde esportes recreativos até esportes de elite de alto nível.

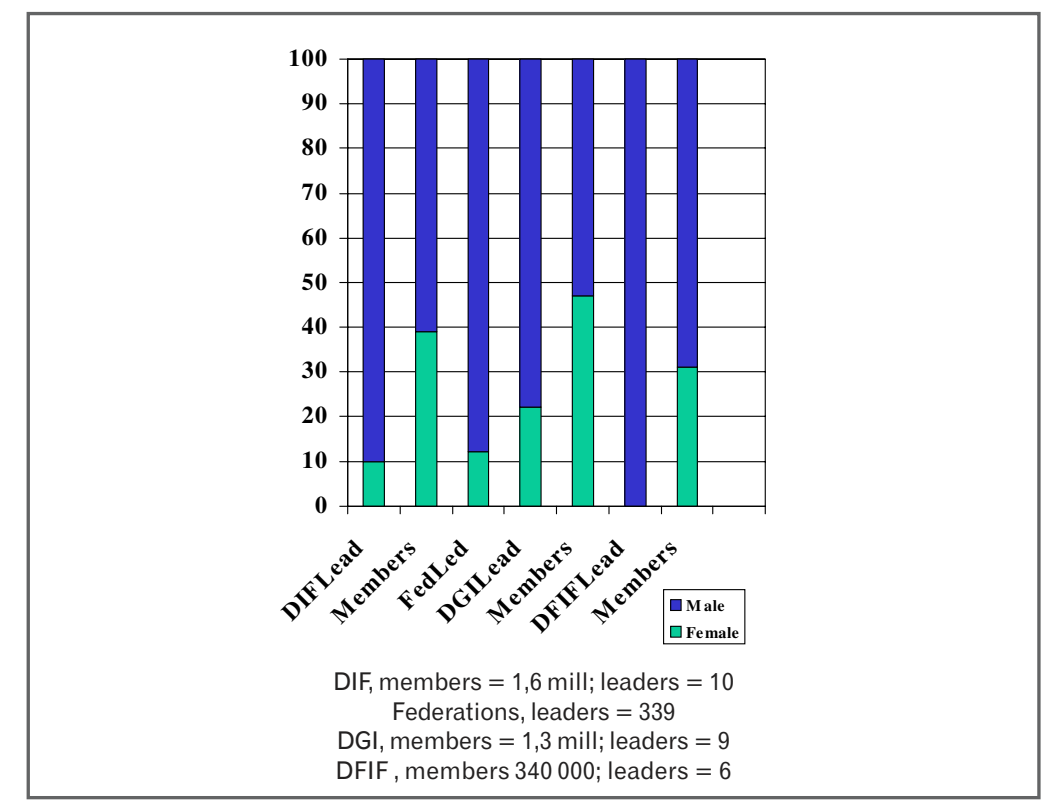

Figura 3. Female leaders in Danish sport organisations

Em 2002, 36\% da população feminina da Dinamarca era membro de um clube esportivo, mas a porcentagem relativamente alta de sócias não se reflete no número de mulheres em comitês deliberativos (Otteses 2003). Em 2000, a porcentagem de mulheres no mais alto comitê deliberativo da DIF era de $10 \%$, na DGI $22 \%$, e na DFIF 0\%. Nos mais altos comitês das cinqüenta e seis federações esportivas, a porcentagem de mulheres é de $12 \%$ sendo que algumas das federações, como a de handebol ou de vôlei, não tinham sequer uma mulher em posições de liderança no topo da hierarquia (Pfister/Habermann 2003).

\section{Estados Unidos}

As estruturas e organizações esportivas nos Estados Unidos se diferenciam consideravelmente das descritas acima. Não exis-

Movimento Porto Alegre, v. 09, n. 2, p. 11-35, maio/agosto de 2003 
te uma federação coordenadora e os principais provedores dos esportes não são os clubes. Certos tipos de esporte, como o golfe ou o tênis, são jogados em clubes mas esses, em sua maioria, não são baseados em trabalho voluntário. As atividades físicas e os esportes são organizados dentro do sistema educacional (escola, universidade), além disso, algumas instituições comerciais oferecem atividades físicas, principalmente fitness. Separadamente, há o esporte profissional, com suas próprias organizações e ligas.

As mais importantes organizações esportivas no campo nãoprofissional nos EUA são: a União Atlética Amadora (AAU), uma organização que coordena as cinqüenta e oito federações esportivas e a Associação Nacional Atlética Universitária (NCAA), que é uma associação voluntária que envolve cerca de mil e duzentas faculdades e universidades e se dedica à administração de jogos interuniversitários.

Um importante papel para o esporte feminino e o crescimento de atletas femininas na última década foi desempenhado pelo "Título IX", emitido em 1972, que é uma emenda educacional ao ato de Direitos Civis de 1964, onde afirma que pessoa alguma poderia ser discriminada em nenhuma atividade ou programa educacional que recebesse assistência financeira federal. De acordo com Costa, "o crescimento da participação do esporte feminino no ensino superior tem sido resultado do cumprimento do Título IX e de processos jurídicos de igualdade sexual". (2003, p.155) Disso resulta que, hoje, cerca de 35\% dos atletas no ensino médio e faculdades são mulheres (idem, 145).

Entretanto, apesar do impacto do Título IX no esporte feminino, uma reforma desse regulamento foi exigida repetidamente, sendo a última vez em 2003, já que supostamente apresentava efeitos negativos em atletas e times masculinos. Os defensores dos esportes femininos, por outro lado, insistiram e insistem que a única maneira de sustentar seus grandes avanços nos últimos 30 anos seria manter um forte compromisso com essa lei federal, inclusive, no seu sentido literal. ${ }^{6}$ Depois de várias audiências nacionais, conduzidas por uma "comissão especial do Título IX", em 2002, ambos os pontos de vista foram apresenta-

6 O Título IX não trouxe apenas vantagens para as mulheres. Graças ao crescimento de recursos financeiros, a disputa por cargos de técnico se tornou mais competitiva, e cada vez mais técnicos homens foram contratados, ver e.g. Costa 2003; ver também Acoasta/Carpenter 2000.

Movimento Porto Alegre, v. 09, n. 2, p. 11-35, maio/agosto de 2003 
dos através de um relatório formal ao Secretário de Educação, Roderick R. Paige, sendo que a decisão final a respeito do futuro do Título IX é aguardada ainda para 2003. Sem dúvida nenhuma, o Título IX teve efeitos positivos nos números e nas oportunidades de atletas femininas. Mas, e a respeito das líderes femininas?

Há excelente informação disponível sobre as organizações baseadas em sexo no sistema esportivo dos EUA. Podemos contar com os "Boletins Raciais e Sexuais" que descrevem os processos de contratação de mulheres e pessoas de cor no esporte americano. Em 2003, Richard Lapchick publicou a $12^{a}$ edição desse relatório com dados aprofundados a respeito das relações de raça e sexo entre atletas, líderes, proprietários e outros funcionários nas ligas profissionais, assim como na NCAA. ${ }^{7}$

Apesar das grandes mudanças e da inclusão crescente das mulheres nos anos 90, a igualdade ainda não foi alcançada na NCAA. Hoje, a NCAA é comandada por um presidente homem e por um comitê executivo com 15 homens e 5 mulheres como membros (http://www.ncaa.org/). No próximo nível de liderança, entre os 41 dirigentes/diretores, a porcentagem de mulheres é de 39\% (Lapchick 2003, 21).

A própria NCAA forneceu dados a respeito das relações de gênero nos departamentos esportivos das suas faculdades associadas (2001/02). Nas instituições associadas à NCAA, as mulheres possuem 16\% dos cargos de presidência, 21\% de Faculty Athletic Representative, ${ }^{8} 17 \%$ de Diretoras Esportivas. ${ }^{9}$ O relatório de Lapchick (2003) revela que nenhuma mulher possui um desses cargos em um dos departamentos de esporte masculino. Nos departamentos de esporte feminino 7,3\% dos diretores esporti-

7 Lapchick 2003. Em 2003, o Boletim Racial e Sexual foi publicado pela primeira vez pelo Instituto de Diversidade e Ética no Esporte da Universidade da Flórida Central, em Orlando. Boletins anteriores foram publicados pelo Centro para o Estudo do Esporte na Sociedade da Universidade do Nordeste. O autor de todos os boletins é Richard Lapchick.

8 O Faculty Athletics Representative (FAR) é responsável pela garantia da integridade acadêmica dos programas esportivos e pela manutenção do bem-estar do estudante atleta. O FAR é nomeado e habilitado pelo reitor da universidade por um mandato renovável de cinco anos. O FAR deve ter o mais alto grau na área, e ser um Professor Associado estável ou um Professor, e ter significativa experiência no comitê ou na administração da Universidade. O FAR é o representante do reitor e da faculdade da Universidade nos assuntos relativos ao esporte.

9 Verojornal, www.ncaa.org/abo8ut/fact_sheet.pdf

Movimento Porto Alegre, v. 09, n. 2, p. 11-35, maio/agosto de 2003 
vos das faculdades pertencentes à Divisão I eram mulheres, 14,4\% nas faculdades da menos prestigiada Divisão II e $25,3 \%$ em faculdades da Divisão III (Lapchick 2003, 35).

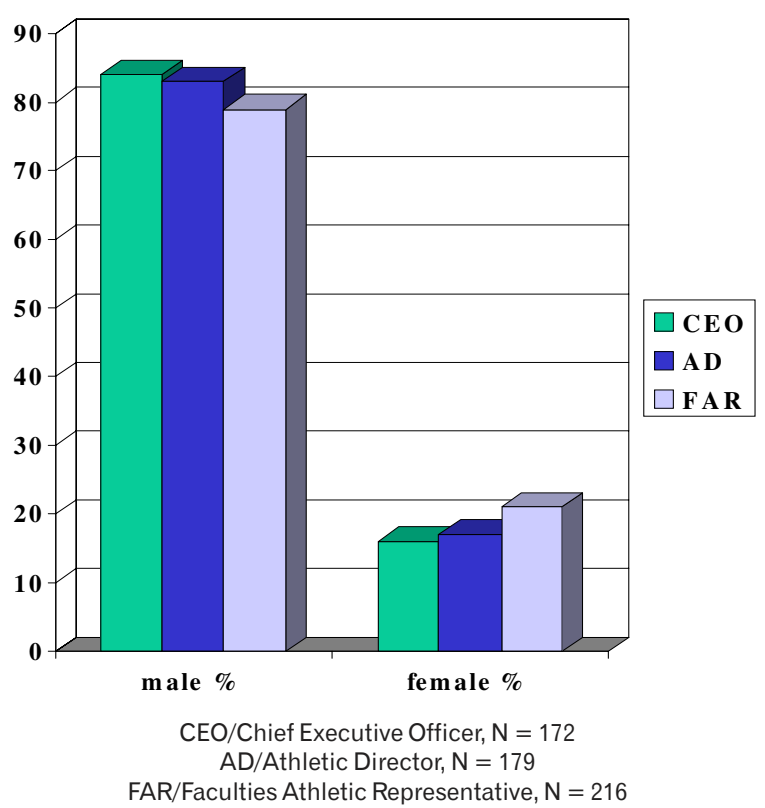

Figura 4. Female leaders in NCAA member institutions

Esses dados colaboram para perceber que a porcentagem de mulheres cresce nas posições de diretores esportivos associados/executivos, mas aqui também a porcentagem de mulheres cai com a importância e prestígio da Divisão. Na Divisão feminina I, 30,2\%, na Divisão II 36,2\% e na Divisão III 46\% dos diretores esportivos executivos eram mulheres..$^{10}$ Mas nenhuma mulher trabalhou nesses cargos em um dos departamentos esportivos masculinos.

10 As instituições da Divisão I têm que promover pelo menos sete esportes masculinos e sete femininos (ou seis masculinos e oito femininos) com dois times para cada gênero. Há um número mínimo de competições e participantes para cada esporte, assim como uma relação de normas. As instituições da Divisão II e da Divisão III têm que promover menos esportes e participar de menos competições.

Movimento Porto Alegre, v. 09, n. 2, p. 11-35, maio/agosto de 2003 
Analisando e interpretando esses dados, temos que levar em consideração que tradicionalmente os departamentos esportivos masculinos e femininos eram separados. Isso significava que, no começo dos anos 70, não só a maioria dos diretores esportivos, mas também $90 \%$ dos treinadores no departamento esportivo feminino eram mulheres. Hoje a porcentagem de mulheres treinando times femininos caiu para $45 \%$ - parcialmente porque o esporte feminino ganhou importância como resultado do "Título IX" - e apenas $2 \%$ dos treinadores de times masculinos são mulheres (ver Lapchick 2003; Costa 2003).

Também na União Atlética Americana (AAU), o poder está nas mãos dos homens. Os 5 Dirigentes Nacionais, o presidente, os 2 vice-presidentes, os secretários gerais e o tesoureiro são todos homens. Das trinta e uma Cadeiras do Esporte Nacional, cinco pertencem a mulheres (cama elástica $\delta$ acrobacias, futebol, hóquei, dança e animação de torcida). ${ }^{11}$

Enquanto as mulheres ganharam algum poder nos jogos interacadêmicos, a dominação masculina no esporte profissional ainda não foi quebrada. Existem cinco ligas profissionais para esportes masculinos: basquete (Associação Nacional de Basquete, NBA), futebol americano (Liga Nacional de Futebol Americano, NHL), basebol (Liga Principal de Basebol, MLB) e futebol (Liga Principal de Futebol, MSL) e uma liga profissional para o basquete feminino (Associação Nacional de Basquete Feminino, WNBA). Essas ligas são pertencentes, em sua maioria, a um grupo de investidores e, algumas vezes, a uma só pessoa. Os proprietários são em maior parte homens sendo que, entre os proprietários majoritários ou principais de times de basquete e beisebol, não há mulheres e entre os proprietários majoritários ou principais de times de futebol americano ou hóquei no gelo a porcentagem de mulheres é de $9 \%$. Cem dos cento e dois times das cinco ligas masculinas têm um presidente homem e apenas duas mulheres possuem esse cargo. Existem cerca de duzentos vice-presidentes de clubes em cada uma das quatro grandes ligas masculinas e vinte e quatro vice-presidentes de clubes no futebol onde a porcentagem de mulheres como vice-presidente fica entre $0 \%$ no futebol e 15\% na NBA (Lapchick 2003, 37).

Nenhuma mulher trabalha como gerente geral (dirigente responsável pelas operações cotidianas do time) nos cinco es-

11 http://www.aausports.org/exec/aau/national_chairs.cfm?publicationID=12

Movimento Porto Alegre, v. 09, n. 2, p. 11-35, maio/agosto de 2003 
portes profissionais masculinos. Na Associação Nacional de Basquete Feminino, nove mulheres (56\%) ocupam esse cargo. O índice de mulheres entre administradores principais nas quatro grandes ligas masculinas está entre $15 \%$ e $29 \%$.

No último ano, as ligas profissionais e a NCAA iniciaram várias "iniciativas diversificadoras", entre outras coisas eles treinam o quadro de empregados para levarem em conta a raça e o sexo ao contratarem novos empregados. A NCAA também conduz oficinas de educação sobre diferenças para os atletas ou oferece concessões para técnicas pertencentes a minorias desenvolverem suas habilidades (Lapchick 2003).

\section{Austrália}

A Austrália é uma nação composta de oito estados com um alto nível de independência. O sistema esportivo na Austrália é uma mistura de instituições e iniciativas governamentais de um lado, e de várias organizações não-governamentais tanto em nível federal e regional, de outro. A principal agência do governo nacional para o desenvolvimento esportivo é a Comissão Australiana de Esportes cujos principais programas são: o Instituto Australiano do Esporte e Austrália Ativa. Austrália Ativa é uma iniciativa que visa o crescimento do compromisso da população com o esporte. ${ }^{12}$

Todos os governos estaduais têm departamentos com funções esportivas e recreativas, todos estabeleceram seus próprios institutos (ou academias) esportivos e todos têm sua própria política esportiva. Governos locais auxiliam na disponibilização de esporte e recreação para a comunidade local.

Organizações nacionais não-governamentais como o Comitê Olímpico Australiano, o Comitê Paraolímpico Australiano, Sports Industry Australia e o Conselho Australiano de Saúde, Educação Física e Recreação também desempenham um importante papel na consolidação e desenvolvimento do esporte naquele país.

Os clubes são os mais importantes incentivadores dos esportes sendo que uma porcentagem relativamente alta da população australiana é associada a um clube esportivo. No entanto, há uma diferença sexual relativamente alta: $33 \%$ da população masculina e apenas $25 \%$ da população feminina está organizada

12 http://www.ausport.gov.au/; http://www.activeaustralia.org/about/

Movimento Porto Alegre, v. 09, n. 2, p. 11-35, maio/agosto de 2003 
em um clube esportivo. Ou, de outra perspectiva, $45 \%$ das pessoas participantes do esporte organizado são mulheres. ${ }^{13}$

Se olharmos para os comitês deliberativos, percebemos que a situação na Austrália não se diferencia muito da situação nos países que já mencionei - pelo menos se levarmos em consideração as organizações esportivas: as mulheres constituem 13\% dos presidentes de organizações esportivas nacionais, $24 \%$ dos treinadores, $9 \%$ dos funcionários dirigentes na área dos esportes de alto nível e $25 \%$ do gerenciamento (Ministerium für Städtebau 2003, 59).

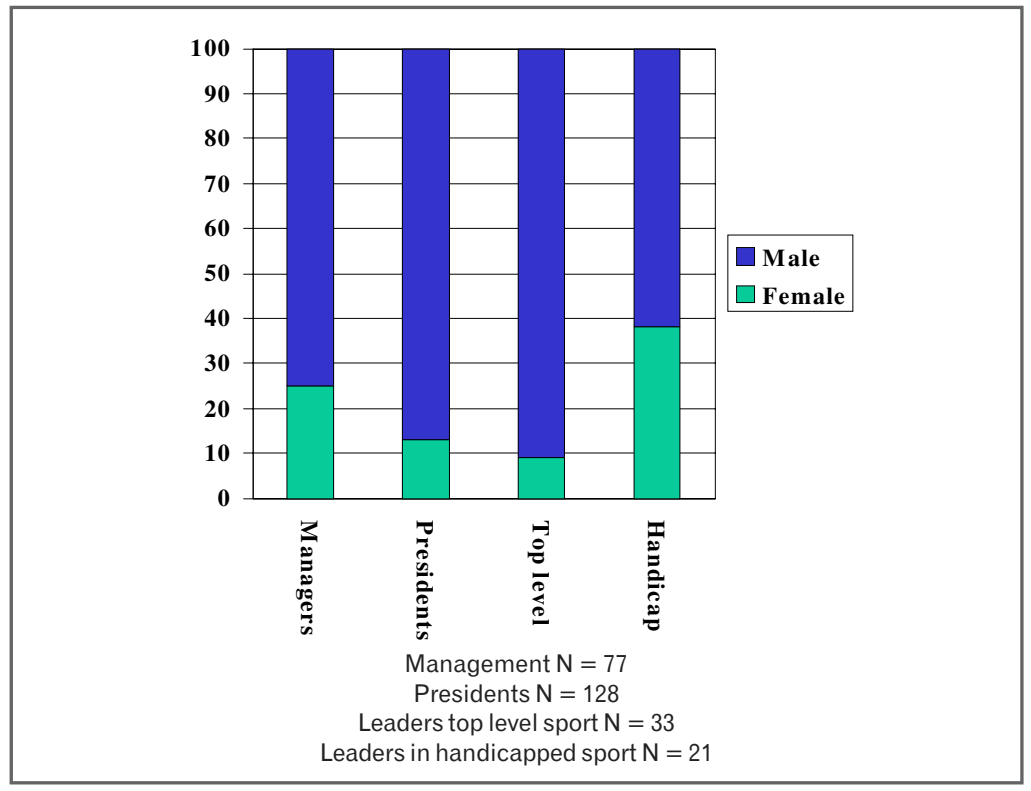

Figura 5. Female leaders in national Australian sport organisations

Elas desempenham um papel bem mais importante na Comissão Esportiva Australiana, mesmo que ainda aí haja, também, uma hierarquia sexual: entre os quatorze funcionários mais graduados no nível executivo há quatro mulheres (29\%); entre as noventa e sete pessoas em cargos de chefia gerencial há trinta mulheres (31\%); e em empregos de secretário há cinqüenta e

13 Agência Australiana de Estatísticas; citada em Ministerium für Städtebau 2003, 59.

Movimento Porto Alegre, v. 09, n. 2, p. 11-35, maio/agosto de 2003 
dois homens e cinqüenta e sete mulheres (59\%) (Ministerium für Städtebau 2003, 59).

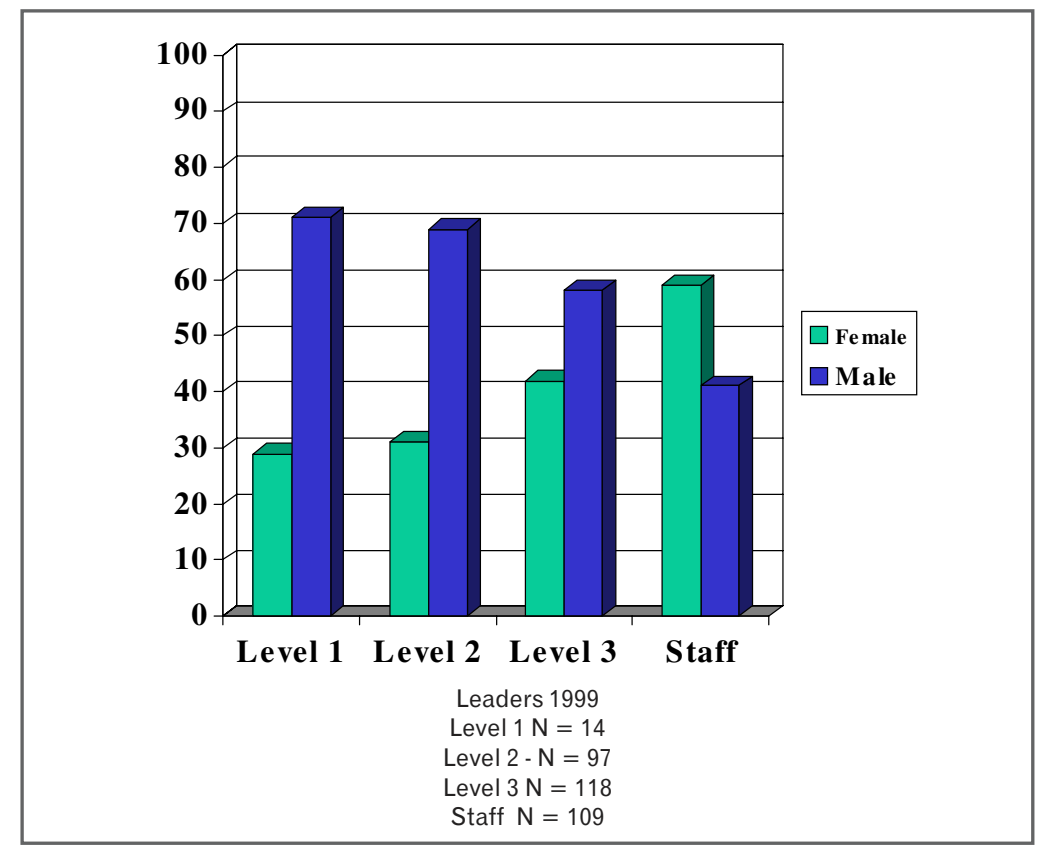

Figura 6. Female Leaders in the Australian Sports Commission

\section{Uma primeira conclusão}

Os comitês deliberativos em organizações e instituições esportivas ainda são dominados por homens e esta constatação não é válida apenas para os países mencionados acima, mas parece ser um fenômeno mundial (ver as contribuições em Hartmann-Tews/Pfister 2003). Na França, 5\% dos presidentes das federações esportivas são mulheres (Dechavanne/Hartmann 2003). Na Espanha, apenas uma das federações esportivas elegeu uma presidente mulher (Puig/Soler 2003). As relações de gênero estão mais equilibradas na Noruega, graças a uma política de cotas que foi introduzida em 1987. Em 1998, 30\% dos membros do conselho executivo das federações esportivas eram mulheres e $38 \%$ dos membros do conselho do Comitê Olímpico

Movimento Porto Alegre, v. 09, n. 2, p. 11-35, maio/agosto de 2003 
Norueguês e Confederação Norueguesa de Esporte eram mulheres (Fasting 2003). ${ }^{14}$

Em relação à hierarquia sexual, as organizações esportivas são um reflexo fiel das sociedades como um todo, caracterizadas por um desequilíbrio de poder e status. Tanto quanto o mundo do esporte, o mercado mundial de trabalho está marcado por uma segregação vertical e horizontal que varia de acordo com o sexo. Deve-se levar em consideração que não é fácil comparar a situação da mulher dentro e fora do esporte em diferentes países, não só pelas diferentes culturas, estruturas sociais e também sistemas esportivos existentes neles, mas também pelas diferentes maneiras com que as estatísticas são estruturadas. Há a questão, por exemplo, de como definir líderes ou - na área do esporte - se técnicos deveriam ser vistos como "líderes", como são em alguns países. Devido a essas restrições que envolvem tempo e espaço, decidi focar minha análise nos dirigentes esportivos.

Apesar do desequilíbrio de poder e da hierarquia baseada nos sexos, há diferenças consideráveis nos vários países analisados. Enquanto na Austrália, por exemplo, 13\% das federações esportivas são presididas por mulheres, cinqüenta e cinco federações esportivas específicas da Alemanha têm apenas três mulheres como presidentes (5\%). E não se deve esquecer que em alguns países como a Austrália houve mudanças consideráveis nos últimos 20 anos.

Um outro tópico importante é a discussão a respeito da mulher e poder nos diferentes países e em organizações internacionais: a baixa representação da mulher em comitês deliberativos é vista como um problema? Isso é discutido? É pesquisado? Há iniciativas e estratégias para mudanças? Eu gostaria apenas de mencionar que há iniciativas para aumentar o número de mulheres nos comitês deliberativos e/ou introduzir tendências baseadas no gênero em organizações esportivas em alguns países como o Canadá e Austrália. Ademais, a nível internacional, há várias organizações e grupos de trabalho preocupados com as mulheres e o esporte, tais como os Grupos de Trabalho sobre a Mulher e o Esporte Internacional e Europeu, a

14 Uma lista extensa de literatura sobre mulheres em posições de liderança de organizações esportivas oferecida pelo Ministerium für Städtebau 2003.

Movimento Porto Alegre, v. 09, n. 2, p. 11-35, maio/agosto de 2003 
Associação Internacional de Educação Física e Esporte para Meninas e Mulheres (IAPESCW) e a Women Sport International. ${ }^{15}$

E há, também, vários projetos de pesquisa em andamento. Entre outros, conduzo com colegas da Dinamarca e Alemanha projetos como o "Mulheres no Topo" cujo objetivo é analisar a situação e identificar as razões pelas quais há falta de mulheres nos comitês deliberativos do esporte organizado.

\section{Mulheres sem poder - origens e razões}

Ao refletir sobre as razões pelas quais as mulheres são minoria nos cargos mais altos do esporte, deve-se ter em mente a história desta prática. Como já foi mencionado, o esporte foi "inventado" e desenvolvido pelo homem e para o homem e, por um longo tempo, "era óbvio" que os homens eram os atletas e também os líderes esportivos "natos". E leva-se muito tempo para mudar as tradições...

Na Europa e na América do Norte, discussões sobre a falta de mulheres em comitês deliberativos de organizações e instituições esportivas datam dos anos 20. As mulheres e o poder se tornaram assunto de exaltados debates no despertar dos movimentos feministas dos anos 70 e 80 (ver as contribuições em Hartmann/Pfister 2003). Entre as estratégias discutidas, estava o sistema de cotas para comitês e cargos de acordo com o sexo, mas isso nunca foi posto em prática. Ao mesmo tempo, as organizações esportivas procuravam explicações como, por exemplo: por que e como foi produzido e reproduzido o desequilíbrio de relações de sexo? Essas discussões levaram a discussões, que iam desde a indiferença da mulher em relação a cargos de liderança de um lado, à resistência de dirigentes do sexo masculino em entregar seu poder e influência do outro. Mas as coisas nunca são tão simples e unilaterais pois a falta de mulheres em posições de liderança é causada por vários processos diferentes e interdependentes.

A seguir gostaria de usar abordagens teóricas usadas para entender o mercado de trabalho para analisar o equilíbrio e relações de poder baseadas no sexo presentes no esporte. Uma das

15 Uma excelente webpage com links de organizações relevantes oferecida pela Associação Canadense para o Avanço da Mulher no Esporte e Atividades Físicas, http://www.caaws.ca/

Movimento Porto Alegre, v. 09, n. 2, p. 11-35, maio/agosto de 2003 
razões para usar essas abordagens é a semelhança nas estruturas de liderança e dominação do homem em posições influentes no esporte e no contingente de trabalhadores. Gostaria de apresentar alguns dos argumentos de ambas abordagens teóricas ligadas ao mercado de trabalho, tanto as baseadas na oferta e na procura. Ambos os lados do mercado de trabalho devem ser levados em consideração, ou seja, os indivíduos que fornecem trabalho e os que o procuram. Assim, ao refletirmos sobre a segregação sexual que existe no mercado de trabalho, fica claro que esta não é uma questão de culpar nem o homem nem a mulher pela hierarquia nas relações de sexo. Pelo contrário, o que deve ser feito é a identificação das origens sociais e estruturais, assim como da lógica de processos decisivos individuais (BeckerSchmidt 1994).

No lado da oferta individual, são fatores importantes a socialização, a qualificação e a orientação profissional, assim como as circunstâncias da vida da mulher, que são influenciadas pela divisão de trabalho de acordo com o sexo (isto é, a responsabilidade da mulher pelo serviço doméstico e a criação dos filhos). O trabalho feminino é caracteristicamente pleno de contradições, descontinuidades e ambivalências, já que o trabalho no contexto familiar é regulado por fatores diferentes e requer qualificações diferentes do que o trabalho vendido como uma mercadoria no mundo do trabalho (Knapp 1988; 1989).

O trabalho e/ou capacidade de liderança da mulher são influenciados por:

1. Fatores individuais como competência, motivação, prioridades, atitudes desenvolvidas no curso da socia-lização (que inclui qualidades e estilo de liderança, e atitudes com relação ao poder, busca pelo prestígio, etc.);

2. Recursos como disponibilidade de horários, assim como recursos econômicos e/ou materiais (capacidade de trabalho, apoio da família e do parceiro, influência na comunidade, importantes contatos e conexões);

3. Reais ou supostos conflitos entre o trabalho no clube e outras áreas da vida (por exemplo, parceiro e/ou filhos).

Este último fator é muito importante: as oportunidades de trabalho e liderança para as mulheres são influenciadas de forma concreta pela sua situação familiar, pois liderança exige uma grande disponibilidade de tempo, energia e concentração, além

Movimento Porto Alegre, v. 09, n. 2, p. 11-35, maio/agosto de 2003 
de flexibilidade. E sendo a mulher responsável pelo serviço doméstico na grande maioria das famílias, seu tempo e energia são escassos e isso é um problema para as mulheres dirigentes que ainda têm que cuidar do bem-estar de seus filhos ou ainda do seu parceiro. Além disso, muitas das líderes voluntárias ainda têm uma profissão de destaque. Assim sendo, líderes femininas têm que carregar uma tripla jornada de trabalho; razões pelas quais não é de se espantar que muitas mulheres de carreira escolham não se comprometer com carreiras profissionais em organizações esportivas.

As abordagens baseadas na oferta de trabalho tentam explicar a segregação presente no mercado de trabalho a partir de análises baseadas nas diferenças entre os sexos e na discriminação das mulheres trabalhadoras. Apontam, ainda, que as exigências das mulheres e as "decisões" que elas tomam são em sua maior parte "lógicas" de um ponto de vista pessoal, pois, freqüentemente, são fruto de pressões do "parceiro/família, emprego/profissão e da sociedade como um todo, com suas regras e papéis.

Enquanto as tradicionais abordagens baseadas na oferta jogam a "culpa" da segregação feminina no mercado na própria mulher e nas suas "decisões", conceitos baseados na procura examinam as estruturas do mercado de trabalho e as estratégias buscadas pelos empregadores (Wilms-Herget 1985; Rabe-Kleberg 1987). De acordo com essa abordagem, as mulheres tendem a ser empregadas, dentro de empresas e instituições, em segmentos sem grande importância devido ao estigma de serem funcionários não-confiáveis pois, como a mulher pode ter filhos e assim dar mais prioridade à família do que ao trabalho, a elas não são confiados cargos de liderança ou não é dada a chance de promoção. O investimento na mão-de-obra só é válido se ela está à disposição da empresa o dia inteiro e ininterruptamente. $\mathrm{O}$ estigma da mulher como um empregado potencialmente nãoconfiável provavelmente tem relação com a ocupação de cargos nos comitês deliberativos do esporte também.

Outros obstáculos encontrados no caminho da carreira das mulheres são os ideais e preconceitos. Mesmo que a adequação da mulher para a liderança não seja abertamente posta em questão, é óbvio que clichês sobre a mulher e sua falta de eficiência e carisma são duradouros e muito difundidos conforme os resultados encontrados em muitos estudos que tematizam essa questão.

Movimento Porto Alegre, v. 09, n. 2, p. 11-35, maio/agosto de 2003 
Tais noções e expectativas também desempenham um papel - conscientemente ou não - na ocupação de vagas de liderança, que também é executada de acordo com o princípio da cooptação. Aqui, certas regras de recrutamento são observadas: novos membros devem, sobretudo, serem apropriados por outros membros e, assim, ajudar a aumentar o prestígio do grupo como um todo. As mulheres - o "sexo oposto" com pouco prestígio - não preenchem nenhuma dessas condições. Além disso, as mulheres - especialmente quando têm um interesse ativo no crescimento feminino - são lembradas como um "aborrecimento". Taxar alguém de "feminista" pode ser uma hábil manobra na disputa com mulheres, primeiro porque evita a solidariedade entre as mulheres (quem gostaria de ser colocado no mesmo grupo que uma "feminista"?), e segundo, evita qualquer mudança na imagem - "uma vez feminista, sempre feminista".

As abordagens baseadas na oferta e na procura podem ser combinadas para formar uma teoria de aculturação, que vê a liderança dentro e fora do esporte como um "mundo homossocial" e que valores e padrões, formas de comunicação e comportamento masculino são a norma (Schultz 1991). Em contraste, as mulheres assumem um disfarce devendo não apenas adaptar-se ao processo de aculturação, mas também obedecer e aplicar regras que nunca tiveram a necessidade e a oportunidade de aprender. Enquanto dirigentes femininas, socializadas em um mundo organizado pelo homem, são admitidas nos grupos dos meninos crescidos, sendo que nunca tiveram nem o apoio de outras mulheres nem mesmo exemplos a serem seguidos para motivá-las e mostrá-las o caminho.

Ao aplicarmos essas regras para o esporte, deve-se levar em conta que os dirigentes esportivos não são contratados ou indicados, mas eleitos, o que torna o processo seletivo muito mais difícil e impenetrável. Além do mais, na questão do trabalho voluntário contra o emprego pago, deve-se perguntar qual exatamente é o "ganho" - seja idealistamente ou materialmente - que induz as pessoas a aceitarem um emprego honorário. $\mathrm{Na}$ avaliação desse "ganho" há, provavelmente, diferenças entre os sexos também. Por exemplo, ter contatos com vários sócios do clube pode ser de grande importância para um homem de negócios, mas sem nenhuma importância para uma professora. Além disso, o prestígio social e a imagem que um cargo honorário traz, pode ser muito mais valioso para o homem do que para a mulher. Mas podemos apenas fazer suposições e não há resultados de estudos quantitativos disponíveis nessa área.

Movimento Porto Alegre, v. 09, n. 2, p. 11-35, maio/agosto de 2003 
Os fatores e processos mencionados acima explicam o teto de vidro que é invisível mas que muito efetivamente impede as mulheres de subirem ao topo (Wirth 2001; ver fig. 7). O teto de vidro nas associações esportivas nos níveis regional, nacional e internacional apenas pode ser analisado e avaliado como uma parte da disposição dos gêneros nas diferentes sociedades, pelo menos das sociedades ocidentais industrializadas. Usando uma abordagem construtivista para o gênero, podemos defini-lo como "um processo de construção social, um sistema de estratificação social e uma instituição que estrutura todo aspecto de nossas vidas, por estar incrustada na família, no trabalho e no estado, assim como na sexualidade, língua e cultura" e - gostaria de adicionar - no esporte (Lorber 1994, 5). O gênero sempre tem uma perspectiva institucional, individual e interacional, o que significa que a relação entre os gêneros em uma sociedade é apropriada por indivíduos que desenvolvem identidades baseadas no sexo e apresentam imagens baseadas no sexo. No momento existe uma concordância geral entre estudiosos do gênero que o sexo tem dimensões diferentes e deve ser interpretado como um processo vitalício com ambivalências e contradições.

Connell (2002) enfatiza o papel de corporações e de "personificações sociais" em processos ligados ao gênero. "Corporações tanto são objetos como também agentes da prática social... As práticas em que corporações estão envolvidas formam estruturas

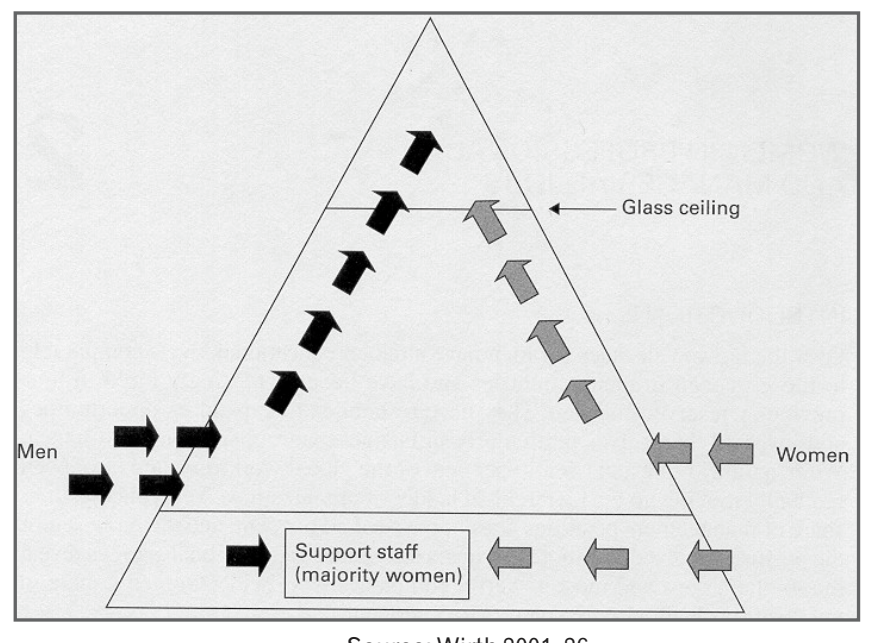

Source: Wirth 2001, 26

Figura 7. The glass ceiling in the organisational pyramid

Movimento Porto Alegre, v. 09, n. 2, p. 11-35, maio/agosto de 2003 
sociais e trajetórias pessoais que, por sua vez, fornecem as condições de novas práticas com as quais as corporações estão dedicadas e envolvidas." (idem 2002, p. 47). O sexo é uma forma específica de personificação social, que se aplica à reprodução. "Sexo é a estrutura das relações sociais que convergem para o campo reprodutivo e o conjunto de práticas (governadas por essa estrutura) que causa diferenças reprodutivas entre corpos em processos sociais" (idem, p. 10). Isso não significa que a reprodução origina as organizações sociais e individuais de gêneros, mas que a esfera da reprodução é um campo, "onde algo social acontece".

O gênero, portanto, não é algo que temos, mas algo que produzimos e fazemos. "O gênero é constantemente criado e recriado nas interações humanas, na vida social e é a estrutura e ordem dessa vida social... ele depende de todos estarem constantemente fazendo o gênero" (Lorber 1994, 13). O gênero é uma representação.

O gênero é uma instituição, as identidades dos gêneros e a representação dos gêneros estão conectadas interdependentemente com o mercado de trabalho e o sistema de símbolos coletivos baseado no sexo. O gênero em um nível institucional, individual e interacional também está embutido nas estruturas e nos sistemas esportivos.

Resumindo, a hierarquia entre os gêneros nas organizações esportivas tem muitas causas, tanto nos níveis individuais como nos estruturais. Um dos fatores mais importantes na falta de líderes femininas no esporte e uma das origens da organização de gêneros no mundo é a responsabilidade da mulher pela reprodução da mão-de-obra, e da estrutura econômica da nossa sociedade, que pode ser descrita como uma economia dupla, no sentido de que o trabalho pago no campo da produção existe lado a lado com o trabalho não-pago da reprodução. O trabalho doméstico (ou seja, serviço doméstico e a criação dos filhos), que as mulheres realizam sem pagamento e sem treinamento prévio, é indispensável para a nossa sociedade. O fato de que garotas e mulheres são preparadas para seus papéis como donas-de-casa e mães no curso dos diversos e vitalícios processos de socialização está ligado profundamente às relações de gênero e é, portanto, algo que não pode ser mudado facilmente.

A divisão do trabalho de acordo com o sexo está tão profundamente ligada a todas as estruturas sociais que uma simples solicitação para que as mulheres se empenhem, ou rápidas e superficiais tentativas de mudança são geralmente condenadas

Movimento Porto Alegre, v. 09, n. 2, p. 11-35, maio/agosto de 2003 
ao fracasso desde o início. Entretanto, de nenhuma forma isso deve levar à conclusão de que as tentativas de reformas não sejam válidas, ou que não vale a pena lutar por mudanças. A discussão a respeito de possíveis estratégias e perspectivas que vão de cotas à orientação de gêneros - deve ser um dos tópicos centrais de instituições e organizações esportivas.

\title{
Líderes femeninas en organizaciones deportivas - Tendencias mundiales
}

Resumen: la presente investigación tiene por objetivo discutir el liderazgo femenino en organizaciones deportivas. Para eso recurre a un análisis de datos cuantitativos de algunos países occidentales con comprobado destaque en el campo deportivo (Alemania, Dinamarca, Estados Unidos de América y Australia), subrayando que, en términos de cargos de dirección en instituciones deportivas, las mujeres todavía no lograron el mismo status que los hombres. Teniendo como referencia teórica los estudios de género la investigación pone en relieve que, mismo con el gran avance que las mujeres han tenido en el mundo del deporte, cuando el tema es el liderazgo y los cargos directivos, todavía hay mucho por conquistar.

Palabras clave: Deporte, Género, Liderazgo Deportiva.

\begin{abstract}
: the objective of the following research is to discuss the female leadership in sport organizations. For that it makes use of an analysis based on quantitative data of some countries with eminence in the sport field (Germany, Denmark, United States and Australia), showing that, in terms of directing posts in sport institutions, women still haven't reached the same status of men. Having as theoretical reference the studies on gender, the research makes evident that, despite the great advance that women have had in the sports world, when regarding to leadership and directive posts there is still much to overcome.

Keywords: Sport, Gender, Sportive Leadership.
\end{abstract}

\section{Referências}

BECKER-SCHMIDT, Regina: Geschlechterverhältnis, Technologieentwicklung und androzentrische Ideologieproduktion. In: Beckenbach, Nils/Treeck, Werner van (Hrsg.): Umbrüche gesellschaftlicher Arbeit. Göttingen 1994, 527-538

CONNELL, Robert W.: Gender and Power. Cambridge 1987.

Movimento Porto Alegre, v. 09, n. 2, p. 11-35, maio/agosto de 2003 
CONNELL, Robert: Gender. Oxford 2002.

COSTA, Margaret: Social issues in American women's sport. Hartmann, Ilse/ Pfister, Gertrud (eds.): Sport and Women. Social Issues in International Perspective. London 2003, 145-161.

DECHAVANNE, Nicole/Hartmann-Tews, Ilse: Sport development and inclusion of women in France. In: Hartmann, Ilse/Pfister, Gertrud (eds.): Sport and Women. Social Issues in International Perspective. London 2003, 70-83.

DeFRANTZ, Anita: Progress made, Pitfalls and Conditions for further Advancement of Women in the Olympic Movement. In: Landry, F./Landry, M./ Yerlès, M. (eds): Sport... The third millenium.

FASTING, Kari: Women and sport in Norway. In: Hartmann, Ilse/Pfister, Gertrud (eds.): Sport and Women. Social Issues in International Perspective. London 2003, 15-35.

FERRIS, Elizabeth: Promoting women sports leaders. In: Olympic Review February-March 2000, 29-32.

HARTMANN, Ilse/Pfister, Gertrud (eds.): Sport and Women. Social Issues in International Perspective. London 2003.

KNAPP, Gudrun Axeli: Arbeitsteilung und Sozialisation: Konstellationen von Arbeitsverm"gen und Arbeitskraft im Lebenszusammenhang von Frauen. In: Beer, U. (Hrsg.): Klasse Geschlecht. Bielefeld 2. Aufl. 1989, S. 267-309.

KNAPP, Gudrun Axeli: Das Konzept „weibliches“ Arbeitsvermögen theoriegeleitete Zugänge, Irrwege, Perspektiven. In: ifg Frauenforschung 6 (1988), H. 4, S. 8-20.

LAPCHICK, Richard: Racial and Gender Report Cards. 2003 http:// www.bus.ucf.edu/sport/public/downloads/media/ides/2003_racial_gender report_card.pdf).

LARSEN, Knud: Idrætsdeltagelse i Danmark - 2002. København 2003.

LINDBERG, Gunilla: IOC missing the gender target. In: Andersen, Jens Sejer (ed.): Play the game. Copenhagen 2003, 17.

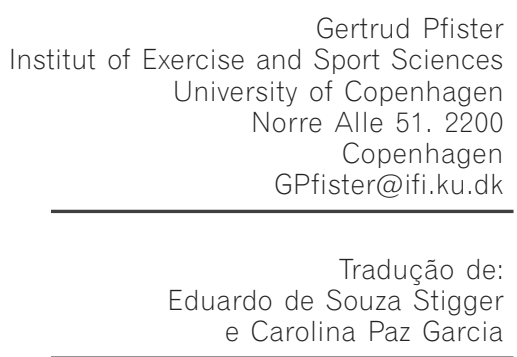

Movimento Porto Alegre, v. 09, n. 2, p. 11-35, maio/agosto de 2003 